\title{
Yielding Actions
}

\author{
ÁNGEL MARTÍNEZ GARCÍA-POSADA \\ Universidad de Sevilla
}

In 1992 Gabriel Orozco, the Mexican artist based in New York, conceived the idea of his work Yielding Stone. The experience consisted in the construction of a plasticine sphere, of approximately the same weight as the artist, which was rolled through the streets of a city. The photograph used to present it summarizes the action and the concept: the soft and imperfect ball appears on a sewage grid, the corrugated marks of these bars have been imprinted on the surface. Later, in different trips, the sculpture has rolled through the streets of each city where it has been exposed, changing its shape slightly, trapping textually layers of urban waste, preserving the trace of its route, reverse trail of the trail in the streets.

That photograph was only one among many other possible, although its choice is correct in his capacity for synthesis. The image presented some obvious facts, and allowed to intuit others deeper or symbolic, as there is an immediate physical trace. In an abstract observation, almost an exercise of Descriptive Geometry, we assume the encounter between a sphere and a plane, enriched by the vibration with respect to the perfection of the forms, since the ball is not an exact sphere and the plane is not either uniform. In an urban register, by induction, we can appreciate the encounter, which the image shows as a low-relief, between the organic entity and the grid. In an historical semblance it would be recognizable the link with the portrait of the human body in a circle of Leonardo's Vitruvian man, as well as the echoes of conceptual greatness, each in its own way, of Cage, Smithson or Beuys, and before all of them, the illuminated path of Duchamp. In an experiential sense, attentive to the biography of the artist, we could speak of the interest of Orozco by the circles and spheres.

The work would also stated a lyric connection among life and works in some artists. The idea that the weight carried by the artist along the streets coincides with his own, introduces an interesting conjecture: to what extent the artist and the work itself, united by the bond of the identical weight and the physical effort of walking together along the same streets, will end up looking like. Because they have known the same places, some marks on the skin will have to be similar, if it must be true that every environment tattoos us, that all dogs end up resembling their owners, or even that it happens the same between the two components of a marriage. Also the intimate connection of the strength of a work establishes a shared footprint, just as the hand of

the artisan ends up resembling his tool of work. The same thing happened, it used to be said, with a portrait and its original model.

It is also possible to claim a political reading of the work, like in other pieces in Orozco's trajectory, the shared common space reflected in the plasticine ball alluded to an area occupied by communities of immigrants or natives, where the ball was paraded, even to the physical constancy of some wounds on their bodies, consequence of an uncomfortable existence when not of some transboundary odyssey. It is true that Orozco has frequently chosen for his actions uprooted territories, of which he appropriates, generating in them silent marks. But other arguments that the piece opens with success acquire special significance: the work in the place and the place in the work, or so many other questions of absolute validity in contemporary architecture, such as the notion of open work or the entropic understanding of creation, the theory of urban archeology and the value of waste, the definition of art as metamorphosis and displacement, the World in migration, or the artificial and natural duality in every artistic process.

It is interesting to look into the efforts of some authors to conjure the unavoidable second principle of thermodynamics, or to reveal the implicit beauty in certain mechanisms of energy transformation, from states of concentration to others of lyrical dissolution in the territory. In the case of the entropic analysis of this work by Orozco, the modest efficiency in this artistic attempt of spell is singular: as the ball accumulates waste from the city where it walks, the loss of matter is balanced for each journey. Some of the ball is lost and remains at the same time in the city, something from the city leaves the streets and goes to roll with the ball, both systems keep their mass even if their initial purity decreases. This is partly a dissolution of the ball in the city, although the resulting material does not lose weight, and simultaneously is a decomposition of urban reality in the artist's work.

The story could well be another fruitful update of that paradoxical figure of the mixture of two matters in time. In its classical formulation, with its patrimonial connotations, would be the story of the ship of Theseus. In his entropic revision, with his landscape interpretations, would be the narrative of the box of white and black sand of Robert Smithson written in "A tour of the Monuments of Passaic, New Jersey" in 1967: 


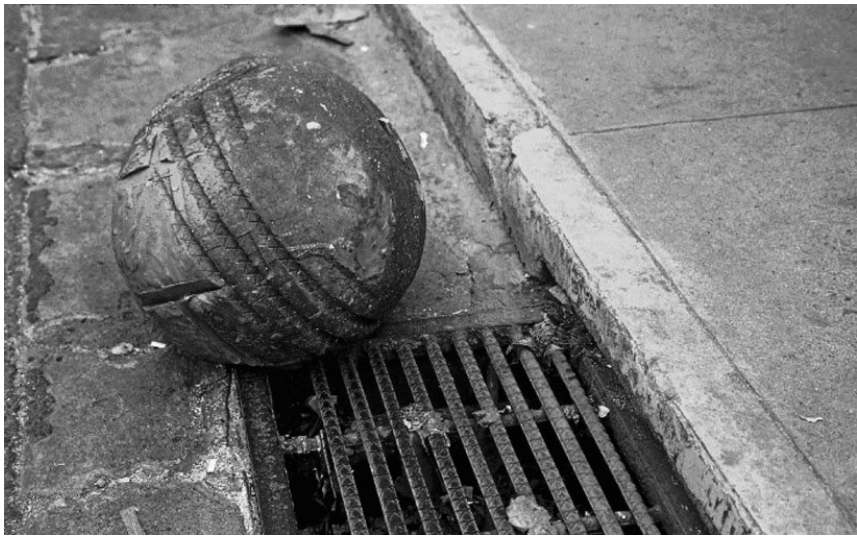

Figure 1: Gabriel Orozco. Yielding Stone. 1992.

Picture in your mind's eye the sand box divided in half with black sand on one side and white sand on the other. We take a child and have him run hundreds of times clockwise in the box until the sand gets mixed and begins to turn grey; after that we have him run anti-clockwise, but the result will not be a restoration of the original division but a greater degree of greyness and an increase of entropy. ${ }^{1}$

Like those grains of sand melted by that kid, Yielding Stone is attractive, the semantic ambiguity of this adjective is precise in this case, due to its rare beauty as well as its magnetic skill.

The city can be identifiable in the ball, or that it could be at least in a rigorous forensic anatomy, although anonymously, and little by little, as it rolls through other places, the successive cities are getting deeper inside, reserving the outer layers to the last stages, as happens with the rings of the trunks of the trees, until forming part of the first of the strata closer to its nucleus, which by this logic, is perhaps more dense. It is remarkable that the plasticine, on contrast, by means of the short relative size of the ball compared with a great city, turns to be inappreciable as it keeps on being stuck on it. Under the aforementioned second law of thermodynamics, the entropy would increase, the ball would wear away, the original plasticine would wane, much of the work would be dust, deposited on the work or on the sidewalks, according to the compensatory equilibrium of the loss of mass that was initially indicated. Jorge Luis Borges himself was able to see all this, in his deepest sense, saying that he was modifying the desert on that visit when he took a handful of sand to drop it again on the dune.

It would be relevant for architecture to register the practice of some artists who carried out works in the same dialectic of matter and energy transfers.

In 1969 Dennis Oppenheim performed Ground MutationShoes Prints, the imprint of his steps on the ground, when for three months he walked with shoes that he had

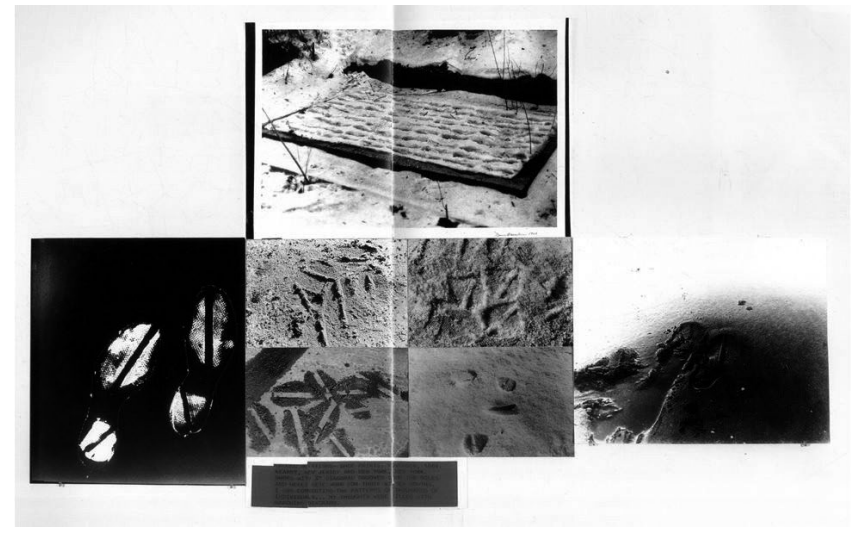

Figure 2: Dennis Oppenheim. Ground Mutation-Shoes Prints. 1971.

modified by cuts in the sole and heel. By this time he had begun to carry out also his series of Transplanted Galleries, in which he moved the drawing in real-scale plan of some exhibition hall to some other receiving territory. Another work by the same artist, Identity Transfers, went through similar codes, from the modesty of an apparently irrelevant action: Oppenheim's daughter transferred the imprint of her thumb to her father, who then did the same with his father, grandfather of the girl, who had just transferred it to the environment, a kind of generational concatenation to reach the earth, exciting in its essentiality. Michael Heizer's Displaced/Replaced Mass exercises, on another scale, also involved exchanges, transferred volumes and dispersed energy, but they were operations that could not be covered by the force of a single Sisyphus on the streets. Years later, in 1987, in a performance with the curious title of Sometimes Do Something Leds to Nothing, Francis Alÿs would stroll his ice block peremptorily through the same streets of Mexico that had previously been traversed by Orozco's ball, leaving a trail of melted water in its countdown until the total disappearance of the frozen sculpture, fused in the asphalt and transformed then, another case of energy that had changed state, in a continuous puddle stretched like a thread.

Like the physical and metaphorical transfer between the artist and the work mentioned above, I have always been attracted by the beautiful transference relationship established between the concrete and the panel that gives it shape. Wine connoisseurs explain in similar terms the importance of wood in the conformation of its wines. There are also experts in scrutinizing the origin of a piece of furniture through the veins of wood. Yielding Stone, the precious title of Orozco's work, refers to all of this. Plasticine is a plastic material, of varied colors, formed by salts of calcium, vaseline and other compounds, suitable to be printed by all these forces, visible and invisible. As in the quote of Anne Sexton about poetry, "out of used furniture she made a tree." 
Some artistic practices point to an interesting field of reflection for architecture nowadays. In the last article by Robert Smithson, published in February 1973 in Artforum, shortly before his death, "Frederick Law Olmsted and the Dialectical Landscape," the artist imagined a conceptual work that recreated the original process of creation of the great park that Olmsted designed in the center of Manhattan and at the same time, according to his idea of artistic as well as operational recycling, restoring Central Park, by then decrepit, and some other landscape needed in that New York in crisis: a sculpture of extracted mud from the pond and deposited somewhere in the city that needed fillings, documented with films and photographs.

Maintenance on The Pond seems long overdue. The mud should be dredged out. This maintenance operation could be treated in terms of art, as a mud extraction sculpture. A documentary treatment with the aid of film or photograph would turn the maintenance into a physical dialectic. The mud could be deposited on a site in the city that needs fill. The transportation of mud would be followed from point of extraction to point of deposition. A consciousness of mud and the realms of sedimentation is necessary in order to understand the landscape as it exists. The magnitude of geological change is still with us, just as it was millions of years ago. Olmsted, a great artist who contended with such magnitudes, sets an example which throws a whole new light on the nature of American art. ${ }^{2}$

Smithson would die right after and that mud sculpture remained a conception he would never see realized. The path of artistic action of synthesis between ecology and industry for urban territories remains today a challenge, perhaps unpostponable, in full force for architects. That operation of balance of energy and mass, action and reaction of clearing and dumping, is another piece of a set of actions over time that should be sobering. The material use

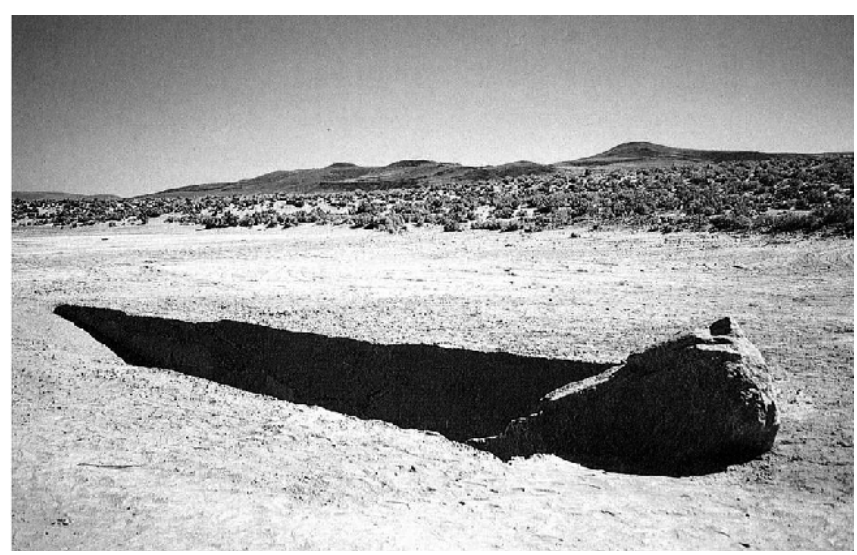

Figure 3: Michael Heizer. Displaced/Replaced Mass.1969. of the ruins or the pre-existences of different times. The connection between the stones extracted from some quarries and their destination points. The relationship between certain molds and the multiplicity of forms produced. The transfer of debris or fillings that served as fill or dredge in other distant places. Some actions of displacement that with an operative logic nourish the architecture of an imaginary of possible practices.

The research that I am just presenting here in brief, as it is an open work in process, collects certain specific cases and proposes generic extrapolations. In short, I would try to reflect creative action as a variation of the principle of conservation of energy, an indissoluble process of dialogue, action and reaction, such as the myth of Sisyphus in which we were at the same time Sisyphus and the stone. This research, cross-sectional and cross-linked, between architecture, art and territory, could point out resonant scenarios for contemporary architectural activity, something that seems opportune, in a situation in which it is necessary to optimize resources and intervention on a reality largely already built.

\section{ENDNOTES}

1. Jack Flam, ed., "A Tour of the Monuments of Passaic, New Jersey," in Robert Smithson: The Collected Writings (London: University of California Press, 1996)

2. Jack Flam, ed., "Frederick Law Olmsted and the Dialectical Landscape" Robert Smithson: The Collected Writings (London: University of California Press, 1996).

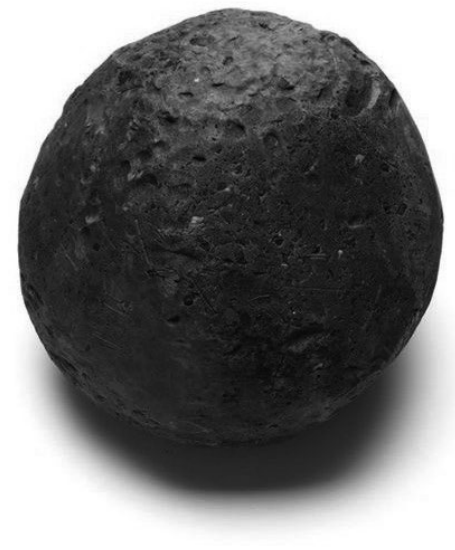

Figure 4: Gabriel Orozco. Yielding Stone. 1992. 